\title{
Expression of aurora kinase $A$ is associated with metastasis-free survival in node-negative breast cancer patients
}

\author{
Wulf Siggelkow ${ }^{1}$, Daniel Boehm², Susanne Gebhard², Marco Battista², Isabel Sicking², Antje Lebrecht ${ }^{2}$, \\ Christine Solbach², Birte Hellwig ${ }^{3}$, Jörg Rahnenführer ${ }^{3}$, Heinz Koelbl ${ }^{2}$, Mathias Gehrmann ${ }^{4}$, Rosemarie Marchan ${ }^{5}$, \\ Cristina Cadenas ${ }^{5}$, Jan G Hengstler ${ }^{5}$ and Marcus Schmidt $2,6^{*}$
}

\begin{abstract}
Background: Inhibitors targeting the cell cycle-regulated aurora kinase A (AURKA) are currently being developed. Here, we examine the prognostic impact of AURKA in node-negative breast cancer patients without adjuvant systemic therapy $(n=766)$.

Methods: AURKA was analyzed using microarray-based gene-expression data from three independent cohorts of node-negative breast cancer patients. In multivariate Cox analyses, the prognostic impact of age, histological grade, tumor size, estrogen receptor (ER), and HER2 were considered.

Results: Patients with higher AURKA expression had a shorter metastasis-free survival (MFS) in the Mainz (HR 1.93; 95\% Cl 1.34 - 2.78; P < 0.001), Rotterdam (HR 1.95; 95\% Cl 1.45- 2.63; P<0.001) and Transbig (HR 1.52; 95\% Cl 1.14-2.04; $\mathrm{P}=0.005$ ) cohorts. AURKA was also associated with MFS in the molecular subtype ER+/HER2- carcinomas (HR 2.10; 95\% Cl 1.70-2.59; $\mathrm{P}<0.001$ ), but not in ER-/HER2- nor in HER2+ carcinomas. In the multivariate Cox regression adjusted to age, grade and tumor size, AURKA showed independent prognostic significance in the ER +/HER2- subtype (HR 1.73; 95\% Cl 1.24-2.42; $\mathrm{P}=0.001$ ). Prognosis of patients in the highest quartile of AURKA expression was particularly poor. In addition, AURKA correlated with the proliferation metagene $(R=0.880 ; P<0.001)$, showed a positive association with grade $(P<0.001)$, tumor size $(P<0.001)$ and HER2 $(P<0.001)$, and was inversely associated with ER status $(P<0.001)$.
\end{abstract}

Conclusions: AURKA is associated with worse prognosis in estrogen receptor positive breast carcinomas. Patients with the highest AURKA expression ( $>75 \%$ percentile) have a particularly bad prognosis and may profit from therapy with AURKA inhibitors.

Keywords: Aurora kinase, Node-negative breast cancer, Breast cancer, Prognosis, Aurora kinase inhibitors

\section{Background}

Aurora kinases A and B are both important for cell cycle progression. They are frequently overexpressed or mutated in human tumor proteins [1,2], and have been implicated in tumor formation and progression [3,4]. Both kinases are highly expressed in several tumor types, including breast, lung, colon, prostate, pancreas, liver,

\footnotetext{
* Correspondence: marcus.schmidt@unimedizin-mainz.de

${ }^{2}$ Department of Obstetrics and Gynecology, Johannes Gutenberg University,

Mainz, Germany

${ }^{6}$ Department of Obstetrics and Gynecology, University of Mainz,

Langenbeckstr. 1, Mainz 55131, Germany

Full list of author information is available at the end of the article
}

skin, stomach, rectum, esophagus, endometrium, cervix, bladder, ovary, and thyroid cancers compared to the corresponding normal tissues [1,2]. Aurora kinase A (AURKA) is also involved in centrosome function and assembly of the mitotic spindle [5], and has been shown to modulate the activity of tumor suppressors such as p53 [1].

Inhibition of aurora kinase in xenograft models results in tumor regression [6]. Furthermore, inhibitors that target this family of kinases are currently under clinical development. These agents selectively target the enzymatic 
activity of aurora kinases by occupying the catalytic adenosine triphosphate (ATP)-binding site [7-9].

Several studies have assessed the importance of aurora kinase A and B in breast cancer. In a mouse model, AURKA overexpression was shown to induce breast tumor formation in mammary epithelium [10]. Moreover, polymorphisms in the AURKA gene are associated with increased risk of primary breast cancer [10,11]. This association is synergistic in its effect on the risk of breast cancer in women with prolonged estrogen exposure [12]. AURKA regulates the transition of cells from the G2 to M phase and has been shown to be responsible for the phosphorylation of BRCA1 [13]. Other studies have assessed the expression of AURKA in human breast cancer tissue. For example, Tanaka et al. [14] investigated 33 cases of invasive ductal carcinoma and found AURKA overexpressed in $94 \%$ of cases. Miyoshi et al. observed elevated expression in $64 \%$ of breast carcinomas using reverse transcription polymerase chain reaction (PCR) in 47 patients [15]. However, a larger study including 112 patients did not find an association between AURKA expression and survival [16]. Furthermore, Nadler et al. observed variable expression of aurora kinase $A$ and $B$ in primary breast tumors [17]. In their study, high levels of AURKA was strongly associated with decreased survival $(P=0.0005)$ and continued to be an independent prognostic marker in the multivariate analysis. High AURKA expression was also associated with high nuclear grade, high HER-2 and progesterone receptor expression. Aurora kinase B expression was not associated with survival [17].

Gene expression profiling has led to a magnitude of different signatures which are related to breast cancer prognosis. In a meta-analysis of publicly available breast cancer gene expression and clinical data, Wiripati and co-workers underscored the important role of proliferation in breast cancer prognosis [18]. Clearly, there are numerous proliferation-associated genes. Martin and coworkers used a novel unsupervised approach to identify a set of genes whose expression predicts prognosis of breast cancer patients [19]. Amongst the most predictive genes for ER positive patients was AURKA, a gene which is a constituent in multiple microarray gene signatures [20-22].

Meanwhile, in a head to head comparison of a large panel of proliferation markers using immunohistochemistry in 3.093 breast carcinomas AURKA outperformed other proliferation markers as an independent predictor of breast cancer-specific survival in ER-positive breast cancer [23]. Finally, a sophisticated analysis of prognostication strategies in breast cancer microarray data sets showed that that the most complex methods were not necessarily better than a univariate model relying on a single gene like AURKA [24]. We could also show that expression of AURKA was associated with survival in node-negative breast cancer in univariate but not in multivariate analysis [25].

In view of the importance of AURKA in malignant progression, together with the current development of aurora kinase inhibitors, we set out to analyze the prognostic significance of AURKA in cohorts of nodenegative breast cancer patients who did not receive adjuvant systemic therapy.

\section{Materials and methods Patients}

This analysis includes gene array data from nodenegative breast cancer patients without adjuvant chemotherapy. The study was approved by the ethical review board of the medical association of Rhineland-Palatinate. The manuscript was prepared in agreement with the reporting recommendations for tumor marker reporting studies [26].

\section{Gene array data for fresh frozen tissue}

Three previously published datasets for untreated nodenegative breast cancer patients were used. The large combined group of 766 patients included the Mainz cohort with 200 patients (Table 1) [27], the Rotterdam cohort with 286 patients (Table 2) [28], and the TRANSBIG cohort with 280 patients (Table 3) [29,30]. These cohorts comprise available microarray datasets for medically untreated node-negative breast cancer which have used metastasis-free survival (MFS) as an end point.

\section{Gene expression profiling and data processing}

For the Mainz, Rotterdam, and TRANSBIG cohorts, the Affymetrix, Inc. (Santa Clara, California) Human Genome U133A Array set and GeneChip System ${ }^{\mathrm{TM}}$ were used to quantify the relative transcript abundance in the breast cancer tissues, as previously described [27], and the robust multiarray average (RMA) algorithm was used for normalization. To analyze AURKA expression from the gene array data, probe set ID 204092_s_at was used in all cohorts.

\section{Statistical analysis}

Survival rates were calculated using the Kaplan-Meier method. Metastasis-free survival was computed from the date of diagnosis to the date of distant metastasis. Survival functions were compared with the Log-rank test. Multivariate Cox survival analyses were performed with inclusion. Categorization was performed as follows: aurora kinase mRNA: < median, $\geq$ median; age: $<50$ years, $\geq 50$ years; HER-2 status, ER status, PR status: negative, positive; histological grade: GI and GII, GIII; pT stage: pT1 $(\leq 2 \mathrm{~cm}), \mathrm{pT} 2$ and pT3 $(>2 \mathrm{~cm})$. Hormone receptor 
Table 1 Clinicopathological characteristics of node negative breast cancer patients (fresh frozen tissue) from the Mainz cohort $(n=200)$

\begin{tabular}{lll}
\hline Characteristics & $\mathbf{n}$ & $\%$ \\
\hline Age at diagnosis & & \\
\hline$<50$ & 49 & 24.5 \\
\hline$\geq 50$ & 151 & 75.5 \\
\hline pT stage & 106 & 53.0 \\
\hline$\leq 2 \mathrm{~cm}$ & 88 & 44.0 \\
\hline$>2 \mathrm{~cm}$ & 6 & 3.0 \\
\hline not documented & & \\
\hline Histological grade & 42 & 21.0 \\
\hline G I & 109 & 54.5 \\
\hline G II & 49 & 24.5 \\
\hline G III & & \\
\hline Estrogen receptor status ${ }^{1}$ & 31 & \\
\hline RNA expression low & 169 \\
\hline RNA expression high & & \\
\hline Progesterone receptor status & \\
\hline RNA expression low & 114 & 57.0 \\
\hline RNA expression high & & \\
\hline
\end{tabular}

Hormone receptor status $^{2}$

RNA expression low

\begin{tabular}{lll}
\hline RNA expression high & 31 & 15.5 \\
\hline & 169 & 84.5 \\
\hline
\end{tabular}

HER2 status

\begin{tabular}{lll}
\hline RNA expression low & 181 & 90.5 \\
\hline RNA expression high & 19 & 9.5
\end{tabular}

Metastasis

\begin{tabular}{lll}
\hline Yes & 47 & 23.5 \\
\hline No & 153 & 76.5 \\
\hline
\end{tabular}

${ }^{1}$ Estrogen, progesterone and HER2 status were derived from RNA levels as described in Schmidt et al., 2010 [34]. ${ }^{2}$ The hormone receptor status is defined as positive when one of either the estrogen or the progesterone receptor status is positive.

status was dichotomized on the basis of the corresponding gene expression values. All p-values are two-sided. As no correction for multiple testing was performed they are descriptive measures. All analyses were performed using R2.12.1.

\section{Results}

To study the prognostic impact of AURKA, we used three publicly accessible Affymetrix gene array data sets, more specifically only node-negative breast cancer patients who did not receive chemotherapy: the Mainz, Rotterdam, and Transbig cohorts (Tables 1, 2, and 3) [27-30]. Expression of AURKA was detectable in all carcinomas and showed a unimodal distribution. AURKA was associated with metastasis-free interval (MFI) in the
Table 2 Clinicopathological characteristics of node negative breast cancer patients (fresh frozen tissue) from the Rotterdam cohort $(\mathbf{n}=\mathbf{2 8 6})$

\begin{tabular}{lll}
\hline Characteristics & $\mathbf{n}$ & $\%$ \\
\hline Estrogen receptor & & \\
\hline RNA expression low & 78 & 27.3 \\
\hline RNA expression high & 208 & 72.7 \\
\hline Progesterone receptor & & \\
\hline RNA expression low & 158 & 55.2 \\
\hline RNA expression high & 128 & 44.8 \\
\hline Hormone receptor status & & \\
\hline RNA expression low & & 26.6 \\
\hline RNA expression high & 76 & 73.4 \\
\hline
\end{tabular}

\begin{tabular}{lll}
\hline RNA expression low & 236 & 82.5 \\
\hline RNA expression high & 50 & 17.5 \\
\hline Metastasis & & \\
\hline Yes & 179 & 62.6 \\
\hline No & 107 & 37.4
\end{tabular}

Estrogen receptor, progesterone receptor and HER-2 status were derived from the gene array data. Cut-points were 8.2 for the estrogen receptor, 11.2 for HER-2, and 4.5 for the progesterone receptor. Log2 transformed gene array data have been used.

${ }^{1}$ The hormone receptor status is positive when either the estrogen or progesterone receptor RNA expression is high.

combined cohort as well as in all three subcohorts using the univariate Cox analysis (Table 4). Similarly, KaplanMeier analysis showed a strong association between high AURKA expression and shorter MFI (Figure 1). Next, we studied whether patients with the highest expression levels of AURKA suffer from a particularly high risk of metastasis. For this purpose, we subdivided the 766 patients into four (Figure 2A) and six (Figure 2B) equal groups with increasing levels of AURKA. This analysis illustrates that patients with AURKA levels between the 25 and 50\% percentile suffer from shorter metastasisfree survival than patients with expression below the $25 \%$ percentile. The $25 \%$ of carcinomas with the highest expression ( $>75 \%$ percentile) have the worse prognosis (Figure 2A). Additional subdivision into six groups of equal size did not allow a further differentiation (Figure 2B).

Breast cancer is not a homogeneous disease, making it necessary to differentiate among the different molecular subtypes. A frequently applied system was introduced by Desmedt et al., differentiating between ER+/HER2-, ER-/HER2- and HER2+ carcinomas [31]. Interestingly, only the ER+/HER2- molecular subtype showed an association between AURKA and MFI, a result relevant for the total cohort (Table 4), as well as for each of the three subcohorts. In contrast, AURKA was not significantly associated with MFI in the ER-/HER2- and in the 
Table 3 Clinicopathological characteristics of node negative breast cancer patients (fresh frozen tissue) from the Transbig cohort $(\mathbf{n}=\mathbf{2 8 0})$

\begin{tabular}{|c|c|c|}
\hline Characteristics & $\mathrm{n}$ & $\%$ \\
\hline \multicolumn{3}{|l|}{ Age at diagnosis } \\
\hline$<50$ & 158 & $\overline{56.4}$ \\
\hline$\geq 50$ & 122 & 43.5 \\
\hline \multicolumn{3}{|l|}{ pT stage } \\
\hline$\leq 2 \mathrm{~cm}$ & 107 & 38.2 \\
\hline$>2 \mathrm{~cm}$ & 173 & 61.8 \\
\hline \multicolumn{3}{|l|}{ Histological grade } \\
\hline$G I+\|$ & 165100 & 58.9 \\
\hline G III & 15 & 35.7 \\
\hline not documented & & 5.4 \\
\hline \multicolumn{3}{|l|}{ Estrogen receptor } \\
\hline RNA expression low & 79 & 28.2 \\
\hline RNA expression high & 201 & 71.8 \\
\hline \multicolumn{3}{|l|}{ Progesterone receptor } \\
\hline RNA expression low & 156 & 55.7 \\
\hline RNA expression high & 124 & 43.3 \\
\hline \multicolumn{3}{|c|}{ Hormone receptor status $^{1}$} \\
\hline \multicolumn{3}{|l|}{ Negative } \\
\hline \multirow[t]{2}{*}{ Positive } & 78 & 27.9 \\
\hline & 202 & 72.1 \\
\hline \multicolumn{3}{|l|}{ HER2 status } \\
\hline RNA expression low & 245 & 87.5 \\
\hline RNA expression high & 35 & 12.5 \\
\hline \multicolumn{3}{|l|}{ Metastasis } \\
\hline Yes & 72 & 74.3 \\
\hline No & 208 & 25.7 \\
\hline
\end{tabular}

Estrogen receptor, progesterone receptor and HER-2 status were derived from the gene array data. Cutpoints were 8.2 for the estrogen receptor, 10.2 for HER-2, and 4.5 for the progesterone receptor. Log2 transformed gene array data have been used.

${ }^{1}$ The hormone receptor status is positive when either the estrogen or progesterone receptor RNA expression is high.

HER2+ carcinomas, respectively. Using multivariate Cox analysis adjusted to age, pTstage and histological grade, AURKA was also significantly associated with MFI in the ER+/HER2- (Table 5) but not in the ER-/HER2(Table 6) carcinomas. The association in the HER2+ subgroup (Table 6) should be interpreted with caution because of the small case number.

Recently, Schmidt and co-workers have identified metagenes that represent biological motifs - proliferation, estrogen receptor and immune system - in breast cancer[27]. AURKA shows a strong correlation with the proliferation metagene (Figure 3A). A weaker inverse correlation was obtained with estrogen receptorassociated genes (Figure 3B). No or only extremely weak correlations were obtained with the B- and T-cell metagenes, respectively (Figure $3 \mathrm{C}$, Figure $3 \mathrm{D}$ ). In addition,
AURKA RNA levels correlated with histological grade $(\mathrm{P}<0.001)$, tumor size $(\mathrm{P}<0.001)$ and HER2 $(\mathrm{P}<0.001)$. Considering the molecular subtypes, AURKA showed higher mRNA levels in ER-/HER2- and HER2+ tumors, whereas expression was lower in ER+/HER2- carcinomas (Figure 4A). A similar pattern was observed for the proliferation metagene (Figure 4B). Similarly as observed for AURKA, also the proliferation metagene was associated with MFI in ER+/HER2- but not in ER-/HER2- nor in HER2+ carcinomas (Additional file 1: Table S1). In conclusion, the correlation of AURKA with metagenes and clinical factors reflects the characteristic pattern of a proliferation-associated gene.

Given the high correlation of AURKA and histological grade and the association of grading with prognosis we analyzed whether there is a real benefit of considering AURKA expression. For this purpose we performed an analysis similarly as Prat and co-workers [32]. To compare the amount of independent prognostic information provided by AURKA we estimated the likelihood ratio statistic in a model that already included grading (Figure 5). The model showed that AURKA provided significant additional information over grading in the cohort of all patients, as well as in the ER+/HER2- and in the HER2+ subgroups. In previous publications Ep-CAM was described as strong prognostic factor in breast cancer [33,34]. The likelihood ratio statistic shows that AURKA also adds independent prognostic information over Ep-CAM in the cohort of all patients as well as in the ER+/HER2- subgroup Additional file 2: Figure S1.

In the present study the Affymetrix probe set 204092_s_at was used as a measure of AURKA expression. However, similar results were obtained also with the probe set 208079_s_at, which highly correlates with 204092_s_at $(\mathrm{R}=0.920 ; \mathrm{P}<0.001)$ (Additional file 1: Figure S1 and Additional file 1: Table S2). A third probe set (208080_at) did not correlate with the other probe sets and should therefore be treated with caution.

\section{Discussion}

Currently, inhibitors of aurora kinases are under preclinical and clinical development $[6,35,36]$. However, the available data on whether high AURKA expression is associated with worse prognosis in breast cancer remain controversial. Nadler et al. [17] reported an association with survival; however, another study with 112 patients was unable to confirm this result [16]. The discrepancy might be explained by the relatively small case numbers. Therefore, we used a well-established cohort of 766 node-negative breast cancer patients [27] to clarify whether AURKA is prognostic. This cohort did not receive chemotherapy, and therefore provides ideal conditions to study the natural course of the disease. In our 
Table 4 AURKA is associated with metastasis-free survival (MFS) in three independent cohorts of systemically untreated node negative breast cancer (combined Mainz, Rotterdam and Transbig cohorts, $n=766$ )

\begin{tabular}{|c|c|c|c|c|c|}
\hline & & Mainz cohort $(n=200)$ & Rotterdam cohort $(n=286)$ & Transbig cohort $(n=280)$ & Combined cohorts $(n=766)$ \\
\hline \multicolumn{6}{|c|}{ A. Univariate Cox analysis } \\
\hline \multirow[t]{3}{*}{ AURKA } & P-value & $<0.001$ & $<0.001$ & 0.005 & $<0.001$ \\
\hline & $\mathrm{HR}$ & 1.927 & 1.952 & 1.520 & 1.669 \\
\hline & $95 \%-\mathrm{Cl}$ & $1.335-2.782$ & $1.448-2.632$ & $1.135-2.036$ & $1.402-1.986$ \\
\hline
\end{tabular}

B. Multivariate Cox analysis of MFS adjusted to established clinical factors (combined Mainz and Transbig cohorts, $\mathrm{n}=465$ )

\begin{tabular}{llll}
\hline & $\mathbf{p}$ & HR & $\mathbf{9 5 \%} \mathbf{C l}$ \\
\hline Age $(<50$ vs. $\geq 50$ years $)$ & 0.392 & 1.180 & $0.808-1.726$ \\
\hline pT stage $(\leq 2 \mathrm{~cm}$ vs. $>2 \mathrm{~cm})$ & 0.005 & 1.812 & $1.192-2.754$ \\
\hline $\begin{array}{l}\text { Histological grade (Grade 1 and 2 } \\
\text { vs. grade 3) }\end{array}$ & 0.087 & 1.529 & $0.940-2.487$ \\
\hline ER status (negative vs. positive) & 0.413 & 1.214 & $0.763-1.931$ \\
\hline HER2 status (negative vs. positive) & 0.415 & 1.248 & $0.732-2.128$ \\
\hline AURKA (continuous variable) & 0.046 & 1.350 & $1.005-1.812$ \\
\hline
\end{tabular}

HR: hazards ratio, 95\%-Cl: 95\% confidence interval. AURKA was analyzed as a continuous variable.
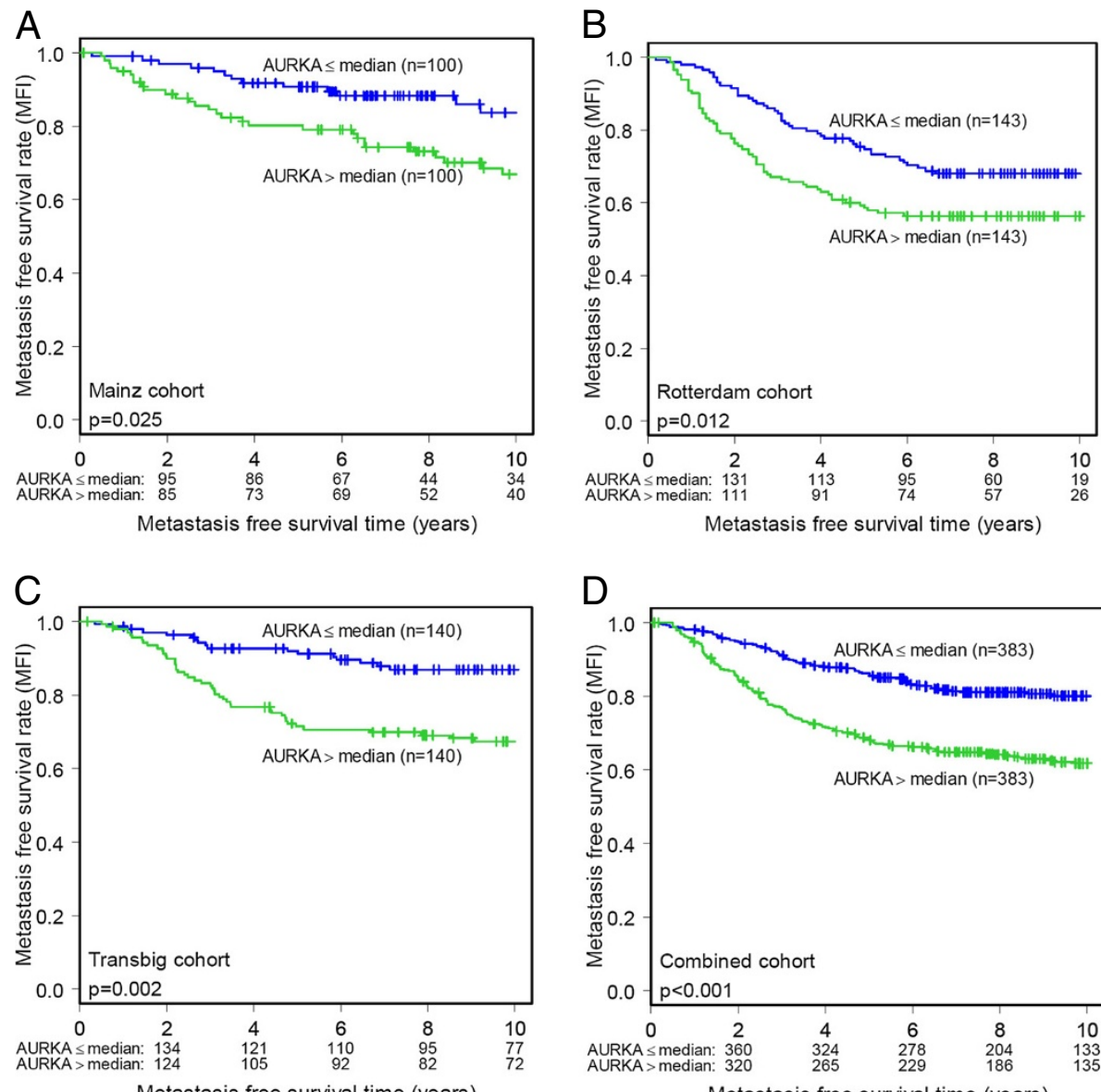

Metastasis free survival time (years)

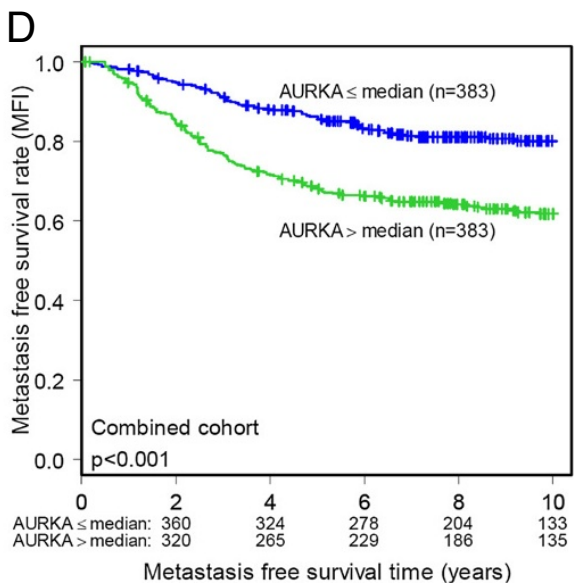

Figure 1 Metastasis-free survival (MFS) in relation to AURKA expression in the individual subcohorts (Mainz, Rotterdam and Transbig) and in the combined cohort. A. Mainz cohort $(n=200)$, B. Rotterdam cohort $(n=286)$, C. Transbig cohort ( $n=280)$, and D. combined cohort $(n=766)$. 


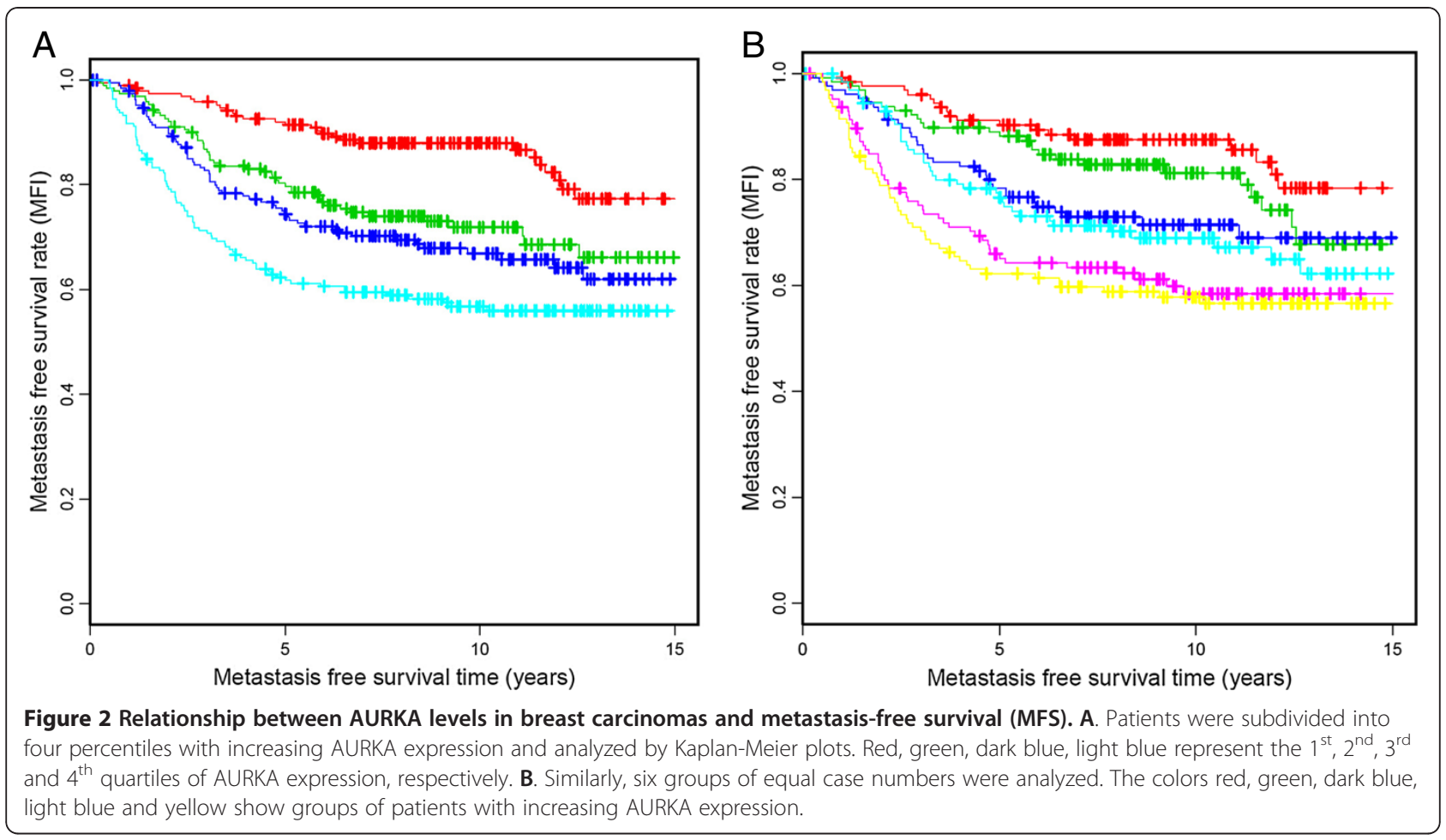

initial analysis, AURKA was not independently associated with survival in the whole cohort of patients [25].

The present study demonstrates that high AURKA expression is associated with worse prognosis in univariate analysis. AURKA was not only significant in the total (combined) cohort, but also in each of the three individual subcohorts (Mainz, Rotterdam, Transbig) that were recruited at different centers. Besides showing an association in the univariate Cox model, AURKA was also significant in the multivariate regression adjusted to

Table 5 Cox analysis of metastasis-free survival (MFS) in the molecular subtypes (ER+/HER; ER-/HER2-; HER2+) according to Desmedt and co-workers [31]

\begin{tabular}{|c|c|c|c|c|c|}
\hline & Mainz cohort $(n=158)$ & Rotterdam cohort $(n=178)$ & Transbig cohort $(n=186)$ & Combined cohorts $(n=522)$ & \\
\hline \multicolumn{6}{|c|}{ A. Univariate analysis } \\
\hline \multicolumn{6}{|c|}{$\mathrm{ER}+/ \mathrm{HER} 2-$} \\
\hline \multirow[t]{4}{*}{ AURKA } & P-value & 0.011 & $<0.001$ & $<0.001$ & $<0.001$ \\
\hline & $\mathrm{HR}$ & 1.786 & 2.916 & 2.174 & 2.100 \\
\hline & $95 \%-\mathrm{Cl}$ & $1.144-2.787$ & $2.022-4.206$ & $1.491-3.171$ & $1.700-2.594$ \\
\hline & Mainz cohort $(n=23)$ & Rotterdam cohort $(n=58)$ & Transbig cohort $(n=59)$ & Combined cohorts $(n=140)$ & \\
\hline \multicolumn{6}{|c|}{ ER-/HER2- } \\
\hline \multirow[t]{4}{*}{ AURKA } & P-value & 0.497 & 0.808 & 0.924 & 0.993 \\
\hline & $\mathrm{HR}$ & 1.534 & 1.103 & 0.967 & 1.002 \\
\hline & $95 \%-\mathrm{Cl}$ & $0.446-5.282$ & $0.498-2.443$ & $0.483-1.934$ & $0.637-1.577$ \\
\hline & Mainz cohort $(n=19)$ & Rotterdam cohort $(n=50=)$ & Transbig cohort $(n=35)$ & Combined cohorts $(n=104)$ & \\
\hline \multicolumn{6}{|l|}{ HER2+ } \\
\hline \multirow[t]{3}{*}{ AURKA } & P-value & 0.298 & 0.840 & 0.100 & 0.402 \\
\hline & $\mathrm{HR}$ & 2.303 & 1.088 & 0.439 & 0.785 \\
\hline & $95 \%-\mathrm{Cl}$ & $0.478-11.091$ & $0.481-2.461$ & $0.165-1.171$ & $0.446-1.382$ \\
\hline
\end{tabular}

AURKA is associated with MFS in the estrogen receptor positive but not in the estrogen receptor negative subtypes. A. Univarate analysis. 
Table 6 Cox analysis of metastasis-free survival (MFS) in the molecular subtypes (ER+/HER; ER-/HER2-; HER2+) according to Desmedt and co-workers [31]

\begin{tabular}{|c|c|c|c|}
\hline & $\mathrm{p}$ & HR & $95 \% \mathrm{Cl}$ \\
\hline \multicolumn{4}{|l|}{ B. Multivariate analysis } \\
\hline \multicolumn{4}{|l|}{ ER+/HER2- $(n=332)$} \\
\hline Age (<50 vs. $\geq 50$ years) & 0.920 & 1.025 & $0.634-1.656$ \\
\hline pT stage $(\leq 2 \mathrm{~cm}$ vs. $>2 \mathrm{~cm})$ & 0.004 & 2.143 & $1.271-3.613$ \\
\hline Histological grade (Grade 1 and 2 vs. grade 3 ) & 0.456 & 1.255 & $0.691-2.283$ \\
\hline \multirow[t]{2}{*}{ AURKA (continuous variable) } & 0.001 & 1.734 & $1.242-2.419$ \\
\hline & p & HR & $95 \% \mathrm{Cl}$ \\
\hline \multicolumn{4}{|l|}{ ER-/HER2- $(n=80)$} \\
\hline Age (<50 vs. $\geq 50$ years) & 0.644 & 0.825 & $0.365-1.865$ \\
\hline pT stage $(\leq 2 \mathrm{~cm}$ vs. $>2 \mathrm{~cm})$ & 0.466 & 1.459 & $0.528-4.028$ \\
\hline Histological grade (Grade 1 and 2 vs. grade 3 ) & 0.590 & 0.768 & $0.294-2.005$ \\
\hline \multirow[t]{2}{*}{ AURKA (continuous variable) } & 0.858 & 0.943 & $0.497-1.791$ \\
\hline & p & HR & $95 \% \mathrm{Cl}$ \\
\hline \multicolumn{4}{|l|}{ HER2+ $(n=53)$} \\
\hline Age (<50 vs. $\geq 50$ years) & 0.018 & 5.072 & $1.327-19.383$ \\
\hline pT stage $(\leq 2 \mathrm{~cm}$ vs. $>2 \mathrm{~cm})$ & 0.485 & 1.510 & $0.475-4.802$ \\
\hline Histological grade (Grade 1 and 2 vs. grade 3 ) & 0.001 & 15.527 & $3.223-74.793$ \\
\hline AURKA (continuous variable) & 0.001 & 0.146 & $0.045-0.466$ \\
\hline
\end{tabular}

AURKA is associated with MFS in the estrogen receptor positive but not in the estrogen receptor negative subtypes. B. Multivariate Cox regression.
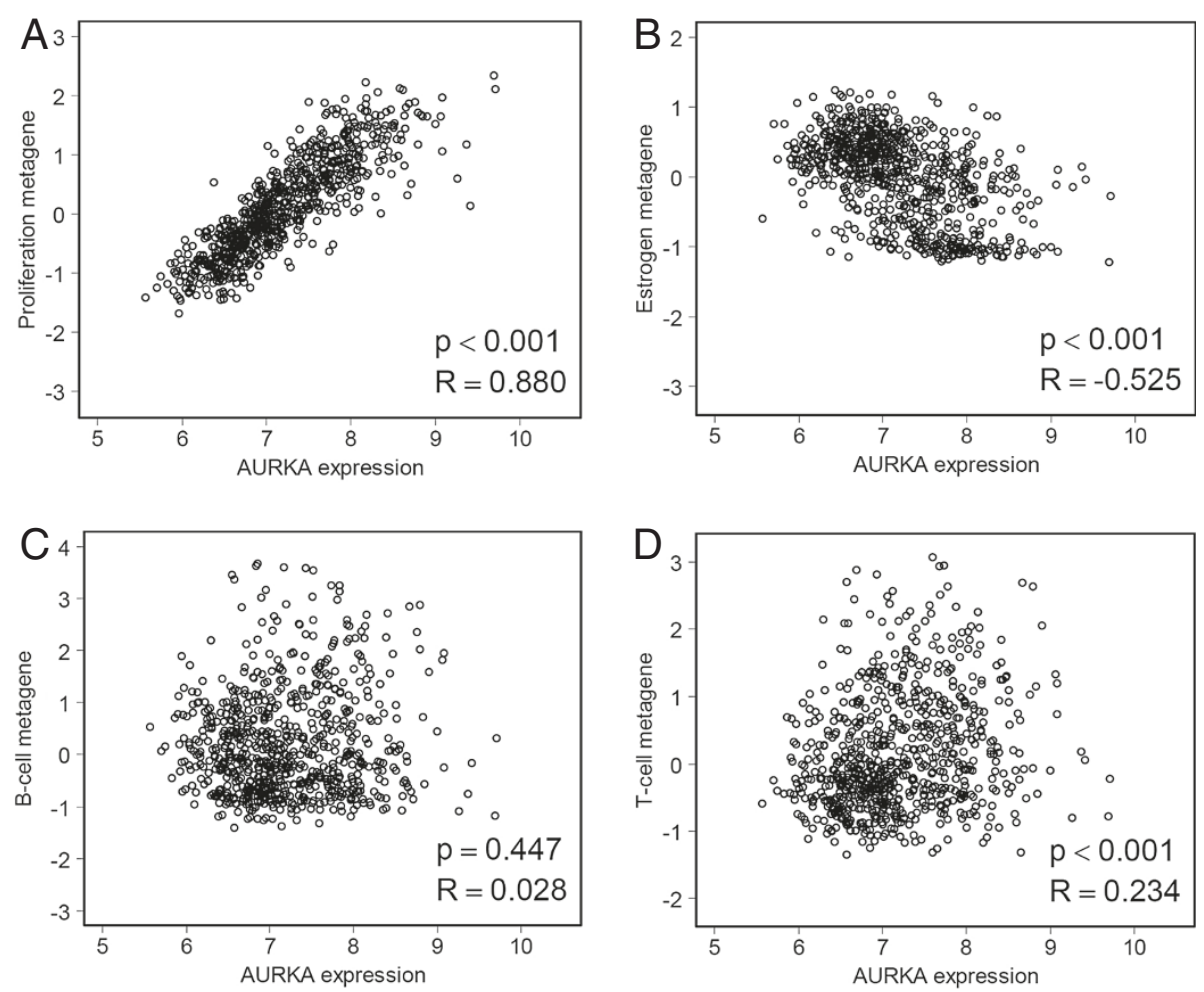

Figure 3 Correlation of AURKA expression with biological motifs expressed by metagenes [27]: A. Proliferation, B. Estrogen receptor, C. B-cell and D. T-cell metagenes. 


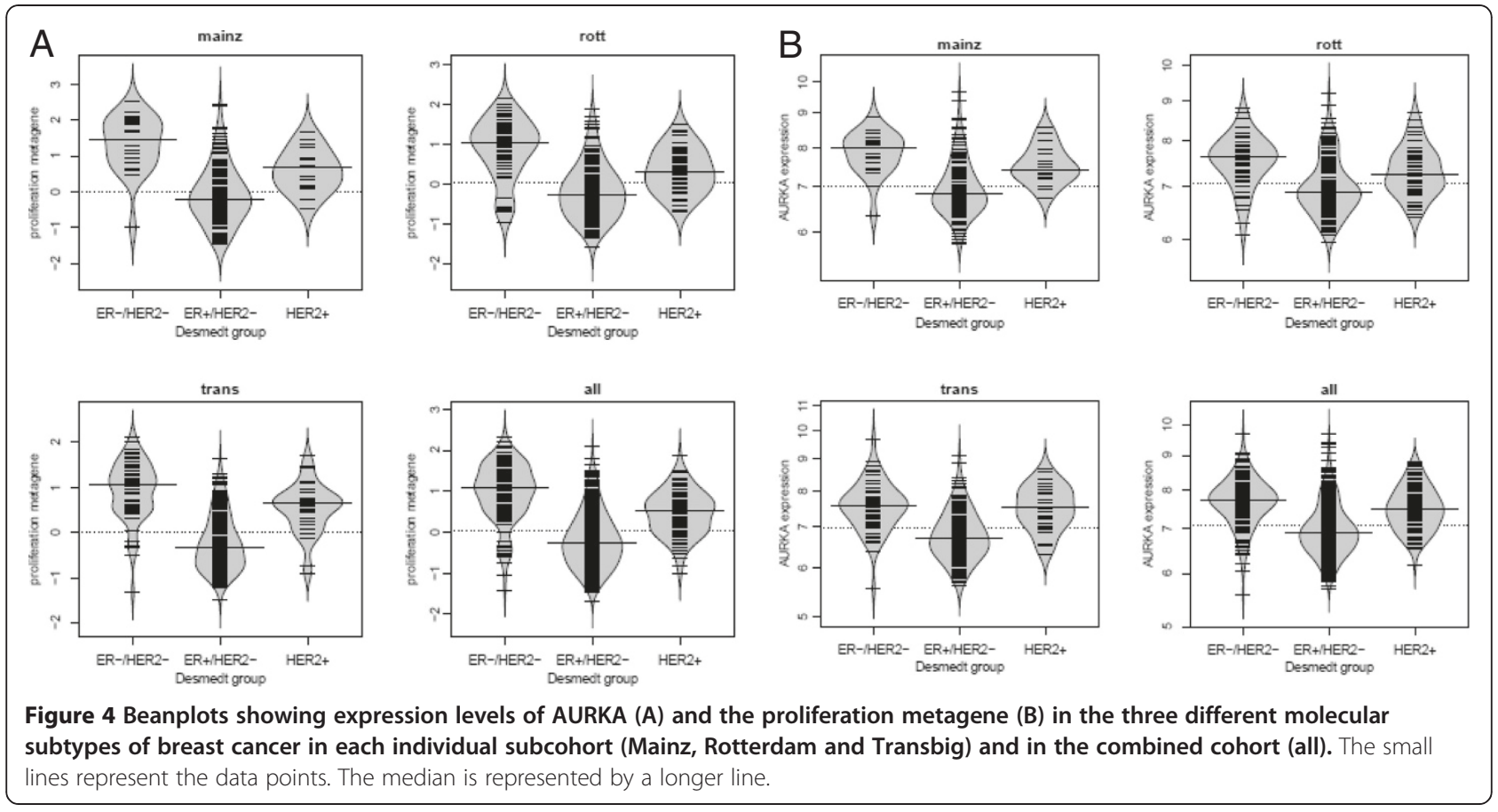

conventional clinical parameters. However, it should be considered that AURKA performed differently in the three molecular subtypes of breast cancer. Whereas a significant association was obtained in the ER+/HER2carcinomas, no association with prognosis was seen in the ER-/HER2- and in the HER2+ carcinomas. The strong prognostic impact of AURKA in ER+/HER2- carcinomas is in agreement with the recent observation made by Haibe-Kains and co-workers [37]. These authors used AURKA in addition to ER and HER2 to robustly define breast cancer subtypes. Expression of AURKA distinguished ER+/HER2- low-risk luminal A like carcinomas from ER+/HER2- high-risk luminal B like carcinomas. In addition to this finding, the different result in estrogen receptor positive and negative patients may have important clinical implications. It is tempting to speculate that aurora kinase A inhibitors may be less efficient in estrogen receptor negative carcinomas where AURKA is not associated with prognosis.

Our findings concerning the different performance of AURKA in the different molecular breast cancer subtypes may explain the contradictory results on the prognostic role of AURKA in the studies of Royce et al. [16] and Nadler et al. [17]. Royce and co-workers did not observe an association of AURKA with survival. However, this study included a relatively high fraction of ERpatients (33\% ER and/or PR positive, 32.1\% ER and PR negative, $34.8 \%$ unknown). In contrast, in our study $79 \%$, $62.2 \%$ and $66.4 \%$ of the patients were ER+ in the Mainz, Rotterdam and Transbig cohorts, respectively. The study group of Nadler also included a relatively high fraction of hormone receptor positive (52\% ER+ and 46\% $\mathrm{PR}+$ ) patients. Therefore, the different numbers of hormone receptor-positive patients in the individual groups may explain the discrepancy.

To illustrate the biological function of AURKA, we analyzed its correlation with metagenes of biological motifs [27]. AURKA strongly correlated with the proliferation metagene. Conversely, no relevant correlations were obtained with the immune (B- and T-cell) metagenes. Therefore, AURKA seems to reflect the degree of proliferation of carcinomas which is in agreement with its biological function in mitosis $[2,5]$.

It might appear controversial that AURKA is not significantly associated with worse prognosis in ER-/HER2and HER2+ tumors although they express even higher levels of AURKA and the proliferation metagene. However, previous studies have already demonstrated that other biological motifs are relevant for the prognosis of ER- and HER2+ carcinomas, particularly an immune cell signature [27] which is best represented by IGKC as a biomarker [38].

\section{Conclusion}

We have shown that AURKA is prognostic in breast cancer patients who did not receive chemotherapy. The prognostic impact of AURKA is most significant in the ER+/HER2- molecular subgroup. The present study has two potential implications for clinical studies with AURKA inhibitors: (i) ER+ patients seem more suitable. 


\section{all patients}

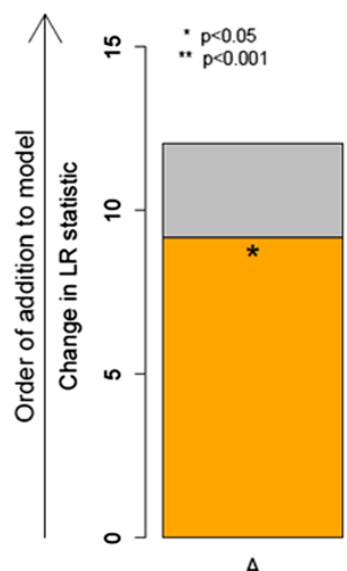

A

ER-/HER2-

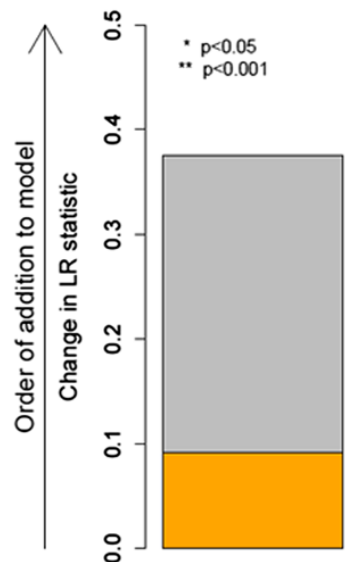

A

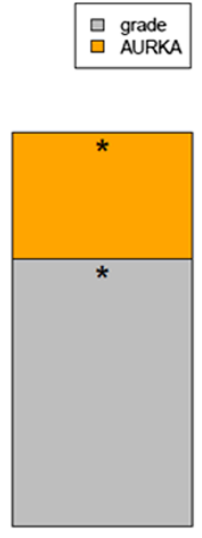

B

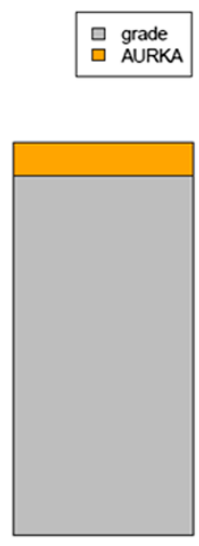

B

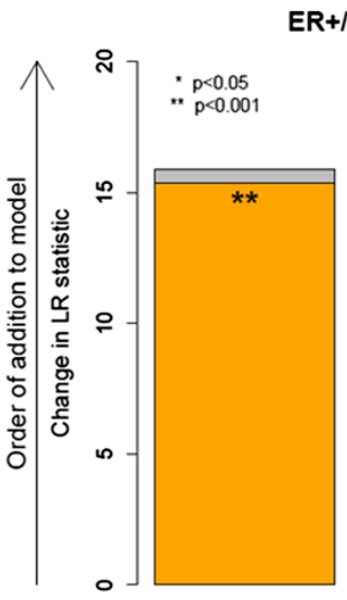

A

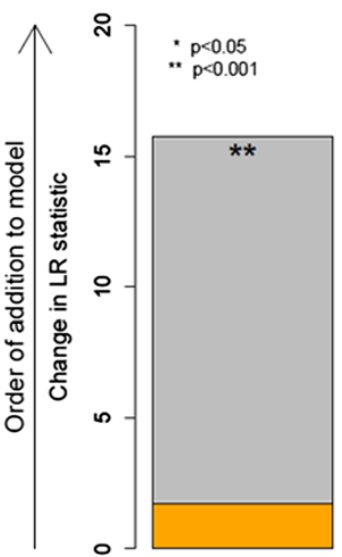

A
HER2+

ER+/HER2-

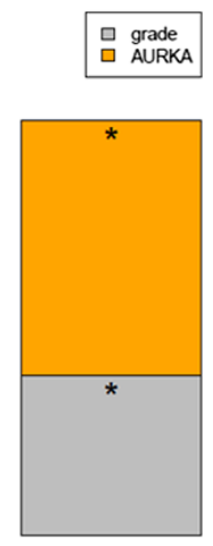

B

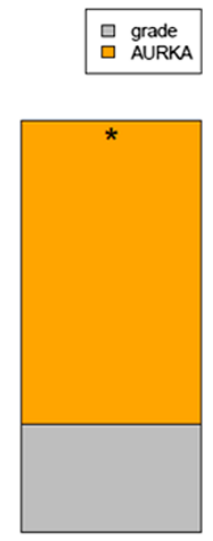

B

Figure 5 Metastasis free survival likeliehood statistics as described by Prat et al., [32]. To compare the amount of independent prognostic information provided by grading (A) and AURKA (B) we estimated the likelihood ratio statistic in a model that already included AURKA (A) or grading (B). The model shows that AURKA provides significant additional information over grading in the cohort of all patients, as well as in the ER+/HER2- and in the HER2+ subgroups (B). Vice versa, grading provides additional information over AURKA only in the subcohort ofHER2+ patients (A).

(ii) Carcinomas with the highest levels (>75\% percentile) of AURKA showed a particularly poor prognosis. Therefore, monitoring AURKA expression will be especially beneficial for patients with high AURKA levels who may profit from chemotherapy with AURKA inhibitors.

\section{Additional files}

Additional file 1: Table S1. Cox analysis of metastasis free survival (MFS) in the single cohorts, in the combined cohort and in the molecular subtypes (ER+/HER2-, ER-/HER2-, HER2+) according to Desmedt (2008). The proliferation metagene is associated with MFI in the estrogen receptor positive but not in the estrogen receptor negative subtypes. Figure S1: Scatter plots showing correlation of AURKA probe sets. Whereas 208079_s_at and 204092_s_at highly correlate with each other the probe set 208080_at shows poor correlation with the other two. Table S2: Similarly as the probe set described in the main manuscript (204092_s_at) the AURKA probe set 208079_s_at is associated with metastasis-free survival (MFS) in the three independent cohorts of systemically untreated node negative breast cancer (combined Mainz, Rotterdam and Transbig cohorts, n=766). HR: hazards ratio, 95\%-Cl: 95\% confidence interval. AURKA was analyzed as a continuous variable. Table S3: Cox analysis of metastasis-free survival (MFS) in the molecular subtypes (ER+/HER; ER-/HER2-; HER2+) according to Desmedt (2008). The AURKA probe set 208079_s_at is associated with MFI in the estrogen receptor positive but not in the estrogen receptor negative subtypes, as described for 204092_s_at in the main manuscript. A. Univariate analysis, B. Multivariate Cox regression

Additional file 2: Figure S1. Metastasis free survival likeliehood statistics as described by Prat et al., (2012). To compare the amount of independent prognostic information provided by Ep-CAM (A) and AURKA (B) we estimated the likelihood ratio statistic in a model that already included AURKA (A) or Ep-CAM (B). The model shows that AURKA provides significant additional information over grading in the cohort of all patients, as well as in the ER+/HER2- subgroups (B). Vice versa, Ep-CAM provides additional information over AURKA only in the cohort of all patients.

\section{Competing interests}

The authors declare that they have no competing interests. 


\section{Authors' contributions}

MS, HK, JGH, MG conceived and designed the experiments. WS, MS, CC, SG, $J G H, M G$ performed the experiments. WS, MS, BH, JGH, CC, JR, SG, DB, CS, AL, MJB, IS, CC, RM, analyzed the data. WS, MS, JGH, CC wrote the paper. All authors read and approved the final manuscript.

\section{Authors' information}

Jan G Hengstler and Marcus Schmidt shared senior authorship.

\begin{abstract}
Author details
'Department of Obstetrics and Gynecology, Diakonischen Dienste Hannove $\mathrm{GmbH}$, Diakoniekrankenhaus Henriettenstiftung und Diakoniekrankenhaus Friederikenstift, Hanover, Germany. ${ }^{2}$ Department of Obstetrics and Gynecology, Johannes Gutenberg University, Mainz, Germany. ${ }^{3}$ Department of Statistics, Dortmund TU, Dortmund, Germany. ${ }^{4}$ Bayer GmbH, Leverkusen, Germany. ${ }^{5}$ IfADo-Leibniz Research Centre for Working Environment and Human Factors (IfADo), Technical University of Dortmund, Dortmund, Germany. ${ }^{6}$ Department of Obstetrics and Gynecology, University of Mainz, Langenbeckstr. 1, Mainz 55131, Germany.
\end{abstract}

Received: 14 May 2012 Accepted: 23 November 2012 Published: 27 November 2012

\section{References}

1. Keen N, Taylor S: Aurora-kinase inhibitors as anticancer agents. Nat Rev Canc 2004, 4:927-936.

2. Fu J, Bian M, Jiang Q, Zhang C: Roles of Aurora kinases in mitosis and tumorigenesis. Mol Canc Res 2007, 5:1-10

3. Carmena M, Earnshaw WC: The cellular geography of aurora kinases. Nat Rev Mol Cell Biol 2003, 4:842-854

4. Bischoff JR, Anderson L, Zhu Y, Mossie K, Ng L, Souza B, Schryver B, Flanagan P, Clairvoyant F, Ginther C, Chan CS, Novotny M, Slamon DJ, Plowman GD: A homologue of drosophila aurora kinase is oncogenic and amplified in human colorectal cancers. EMBO J 1998, 17:3052-3065.

5. Marumoto T, Zhang D, Saya H: Aurora-A - a guardian of poles. Nat Rev Canc 2005, 5:42-50.

6. Harrington EA, Bebbington D, Moore J, Rasmussen RK, Ajose-Adeogun AO, Nakayama T, Graham JA, Demur C, Hercend T, Diu-Hercend A, Su M, Golec $J M C$, Miller KM: VX-680, a potent and selective small-molecule inhibitor of the Aurora kinases, suppresses tumor growth in vivo. Nat Med 2004, 10:262-267.

7. Ditchfield C, Johnson VL, Tighe A, Ellston R, Haworth C, Johnson T, Mortlock A, Keen N, Taylor SS: Aurora B couples chromosome alignment with anaphase by targeting BubR1, Mad2, and Cenp-E to kinetochores. J Cell Biol 2003, 161:267-280

8. Hauf S, Cole RW, LaTerra S, Zimmer C, Schnapp G, Walter R, Heckel A, van Meel J, Rieder CL, Peters J: The small molecule Hesperadin reveals a role for Aurora B in correcting kinetochore-microtubule attachment and in maintaining the spindle assembly checkpoint. J Cell Biol 2003, 161:281-294.

9. Katayama H, Ota T, Jisaki F, Ueda Y, Tanaka T, Odashima S, Suzuki F, Terada Y, Tatsuka M: Mitotic kinase expression and colorectal cancer progression. J Natl Canc Inst 1999, 91:1160-1162.

10. Cox DG, Hankinson SE, Hunter DJ: Polymorphisms of the AURKA (STK15/ aurora kinase) gene and breast cancer risk (United States). Canc Causes Control 2006, 17:81-83.

11. Fletcher O, Johnson N, Palles C, dos Santos Silva I, McCormack V, Whittaker J. Ashworth A, Peto J: Inconsistent association between the STK15 F311 genetic polymorphism and breast cancer risk. J Natl Canc Inst 2006, 98:1014-1018.

12. Dai Q, Cai Q, Shu X, Ewart-Toland A, Wen W, Balmain A, Gao Y, Zheng W: Synergistic effects of STK15 gene polymorphisms and endogenous estrogen exposure in the risk of breast cancer. Canc Epidemiol Biomarkers Prev 2004, 13:2065-2070

13. Ouchi M, Fujiuchi N, Sasai K, Katayama H, Minamishima YA, Ongusaha PP, Deng C, Sen S, Lee SW, Ouchi T: BRCA1 phosphorylation by Aurora-A in the regulation of G2 to M transition. J Biol Chem 2004, 279:19643-19648.

14. Tanaka T, Kimura M, Matsunaga K, Fukada D, Mori H, Okano Y: Centrosomal kinase AIK1 is overexpressed in invasive ductal carcinoma of the breast. Canc Res 1999, 59:2041-2044.
15. Miyoshi Y, Iwao K, Egawa C, Noguchi S: Association of centrosomal kinase STK15/BTAK mRNA expression with chromosomal instability in human breast cancers. Int J Canc 2001, 92:370-373

16. Royce ME, Xia W, Sahin AA, Katayama H, Johnston DA, Hortobagyi G, Sen S, Hung M: STK15/Aurora-A expression in primary breast tumors is correlated with nuclear grade but not with prognosis. Cancer 2004, 100:12-19.

17. Nadler Y, Camp RL, Schwartz C, Rimm DL, Kluger HM, Kluger Y: Expression of Aurora A (but not Aurora B) is predictive of survival in breast cancer. Clin Canc Res 2008, 14:4455-4462.

18. Wirapati P, Sotiriou C, Kunkel S, Farmer P, Pradervand S, Haibe-Kains B, Desmedt C, Ignatiadis M, Sengstag T, Schütz F, Goldstein DR, Piccart M, Delorenzi M: Meta-analysis of gene expression profiles in breast cancer: toward a unified understanding of breast cancer subtyping and prognosis signatures. Breast Canc Res 2008, 10:R65.

19. Martin KJ, Patrick DR, Bissell MJ, Fournier MV: Prognostic breast cancer signature identified from 3D culture model accurately predicts clinical outcome across independent datasets. PLoS One 2008, 3:e2994.

20. van Veer LJ't, Dai H, van de Vijver MJ, He YD, Hart AAM, Mao M, Peterse HL, van der Kooy K, Marton MJ, Witteveen AT, Schreiber GJ, Kerkhoven RM, Roberts C, Linsley PS, Bernards R, Friend SH: Gene expression profiling predicts clinical outcome of breast cancer. Nature 2002, 415:530-536.

21. Sotiriou C, Wirapati P, Loi S, Harris A, Fox S, Smeds J, Nordgren H, Farmer P, Praz V, Haibe-Kains B, Desmedt C, Larsimont D, Cardoso F, Peterse H, Nuyten D, Buyse M, van de Vijver MJ, Bergh J, Piccart M, Delorenzi M: Gene expression profiling in breast cancer: understanding the molecular basis of histologic grade to improve prognosis. J Natl Canc Inst 2006, 98:262-272.

22. Teschendorff AE, Mook S, Reyal F, van Vliet MH, Armstrong NJ, Horlings HM, de Visser KE, Kok M, Teschendorff AE, Mook S, van Veer L't, Caldas C, Salmon RJ, van de Vijver MJ, Wessels LFA: A comprehensive analysis of prognostic signatures reveals the high predictive capacity of the proliferation, immune response and RNA splicing modules in breast cancer. Breast Canc Res 2008, 10:R93.

23. Ali HR, Dawson S, Blows FM, Provenzano E, Pharoah PD, Caldas C: Aurora kinase A outperforms Ki67 as a prognostic marker in ER-positive breast cancer. Br J Canc 2012, 106:1798-1806.

24. Haibe-Kains B, Desmedt C, Sotiriou C, Bontempi G: A comparative study of survival models for breast cancer prognostication based on microarray data: does a single gene beat them all? Bioinformatics 2008, 24:22002208 .

25. Schmidt M, Petry I, Boehm D, Gebhard S, Lebrecht A, Koelbl H, Gehrmann $\mathrm{M}$, Hengstler JG: Prognostic significance of Aurora kinase A expression in three cohorts of node-negative breast cancer patients. Canc Res 2010, 70:33s.

26. McShane LM, Altman DG, Sauerbrei W, Taube SE, Gion M, Clark GM: REporting recommendations for tumor MARKer prognostic studies (REMARK). Breast Canc Res Treat 2006, 100:229-235.

27. Schmidt $M$, Böhm D, von Törne $C$, Steiner E, Puhl A, Pilch $H$, Lehr $H_{\text {, }}$ Hengstler JG, Kölbl H, Gehrmann M: The humoral immune system has a key prognostic impact in node-negative breast cancer. Canc Res 2008, 68:5405-5413

28. Wang $Y$, Klijn JGM, Zhang Y, Sieuwerts AM, Look MP, Yang F, Talantov D, Timmermans M, Meijer-van Gelder ME, Yu J, Jatkoe T, Berns EMJJ, Atkins D, Foekens JA: Gene-expression profiles to predict distant metastasis of lymph-node-negative primary breast cancer. Lancet 2005, 365:671-679

29. Desmedt C, Piette F, Loi S, Wang Y, Lallemand F, Haibe-Kains B, Viale G, Delorenzi M, Zhang Y, d'Assignies MS, Bergh J, Lidereau R, Ellis P, Harris AL, Klijn JGM, Foekens JA, Cardoso F, Piccart MJ, Buyse M, Sotiriou C: Strong time dependence of the 76-gene prognostic signature for nodenegative breast cancer patients in the TRANSBIG multicenter independent validation series. Clin Canc Res 2007, 13:3207-3214.

30. Loi S, Haibe-Kains B, Desmedt C, Lallemand F, Tutt AM, Gillet C, Ellis P, Harris A, Bergh J, Foekens JA, Klijn JGM, Larsimont D, Buyse M, Bontempi G, Delorenzi M, Piccart MJ, Sotiriou C: Definition of clinically distinct molecular subtypes in estrogen receptor-positive breast carcinomas through genomic grade. J Clin Oncol 2007, 25:1239-1246.

31. Desmedt C, Haibe-Kains B, Wirapati P, Buyse M, Larsimont D, Bontempi G, Delorenzi M, Piccart M, Sotiriou C: Biological processes associated with breast cancer clinical outcome depend on the molecular subtypes. Clin Canc Res 2008, 14:5158-5165. 
32. Prat A, Parker JS, Fan C, Perou CM: PAM50 assay and the three-gene model for identifying the major and clinically relevant molecular subtypes of breast cancer. Breast Canc Res Treat 2012, 135:301-306

33. Schmidt M, Hasenclever D, Schaeffer M, Boehm D, Cotarelo C, Steiner E, Lebrecht A, Siggelkow W, Weikel W, Schiffer-Petry I, Gebhard S, Pilch H, Gehrmann M, Lehr H, Koelbl H, Hengstler JG, Schuler M: Prognostic effect of epithelial cell adhesion molecule overexpression in untreated nodenegative breast cancer. Clin Canc Res 2008, 14:5849-5855.

34. Schmidt M, Petry IB, Böhm D, Lebrecht A, von Törne C, Gebhard S, GerholdAy A, Cotarelo C, Battista M, Schormann W, Freis E, Selinski S, Ickstadt K, Rahnenführer J, Sebastian M, Schuler M, Koelbl H, Gehrmann M, Hengstler JG: Ep-CAM RNA expression predicts metastasis-free survival in three cohorts of untreated node-negative breast cancer. Breast Canc Res Treat 2011, 125:637-646.

35. Gully CP, Zhang F, Chen J, Yeung JA, Velazquez-Torres G, Wang E, Yeung SJ, Lee M: Antineoplastic effects of an Aurora B kinase inhibitor in breast cancer. Mol Canc 2010, 9:42.

36. Hardwicke MA, Oleykowski CA, Plant R, Wang J, Liao Q, Moss K, Newlander K, Adams JL, Dhanak D, Yang J, Lai Z, Sutton D, Patrick D: GSK1070916, a potent Aurora B/C kinase inhibitor with broad antitumor activity in tissue culture cells and human tumor xenograft models. Mol Canc Ther 2009, 8:1808-1817.

37. Haibe-Kains B, Desmedt C, Loi S, Culhane AC, Bontempi G, Quackenbush J, Sotiriou C: A three-gene model to robustly identify breast cancer molecular subtypes. J Natl Canc Inst 2012, 104:311-325.

38. Schmidt M, Hellwig B, Hammad S, Othman A, Lohr M, Chen Z, Boehm D, Gebhard S, Petry I, Lebrecht A, Cadenas C, Marchan R, Stewart JD, Solbach C, Holmberg L, Edlund K, Kultima HG, Rody A, Berglund A, Lambe M. Isaksson A, Botling J, Karn T, Müller V, Gerhold-Ay A, Cotarelo C, Sebastian $\mathrm{M}$, Kronenwett R, Bojar $\mathrm{H}$, Lehr $\mathrm{H}$, et al: A comprehensive analysis of human gene expression profiles identifies stromal immunoglobulin $\mathrm{K} C$ as a compatible prognostic marker in human solid tumors. Clin Canc Res Offic J Am Assoc Canc Res 2012, 18:2695-2703.

doi:10.1186/1471-2407-12-562

Cite this article as: Siggelkow et al: Expression of aurora kinase A is associated with metastasis-free survival in node-negative breast cancer patients. BMC Cancer 2012 12:562.

\section{Submit your next manuscript to BioMed Central and take full advantage of:}

- Convenient online submission

- Thorough peer review

- No space constraints or color figure charges

- Immediate publication on acceptance

- Inclusion in PubMed, CAS, Scopus and Google Scholar

- Research which is freely available for redistribution 